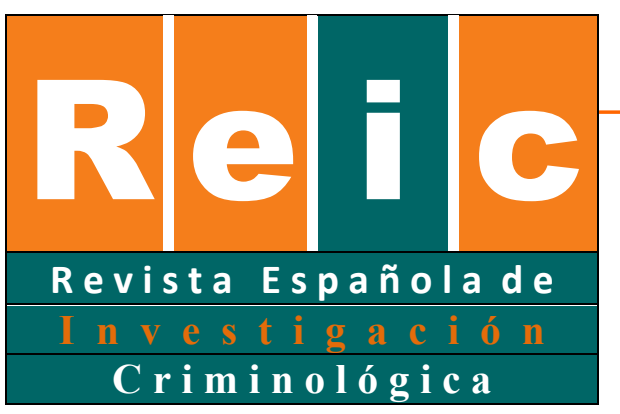

Molina Caballero

\title{
Justicia juvenil y prácticas restaurativas. \\ Trazos para el diseño de programas y \\ para su implementación, de R. Calvo, \\ NED Ediciones, 2018
}

\author{
Por: María Jesús Molina Caballero \\ Universidad de Málaga
}

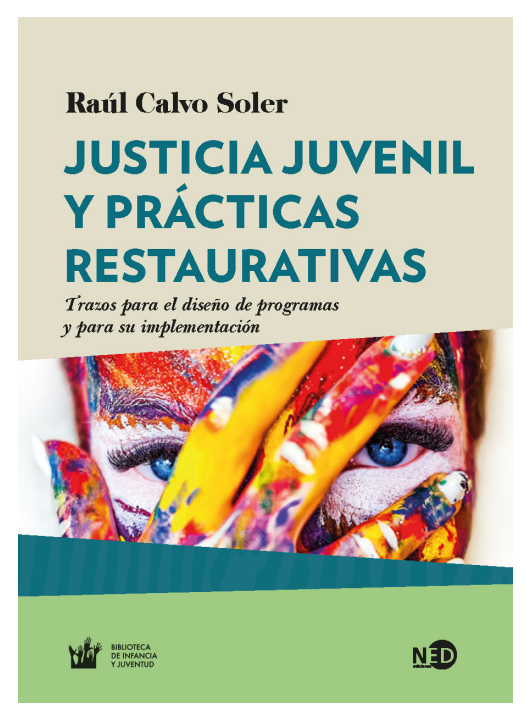

El conflicto, como algo inherente a la sociedad y a la convivencia de sus miembros, encuentra en muy diferentes ramas del conocimiento un hueco para su análisis y reflexión. Desde la Psicología a la Antropología, pasando por el Derecho y la Criminología, sin olvidar la novedosa Conflictología, el estudio de los retos de la convivencia en sociedad y sus disrupciones es objeto de análisis desde muy diferentes perspectivas.

La obra que recensionamos nos adentra en el mundo del conflicto penal, especialmente en el marco de la delincuencia juvenil, para hacernos reflexionar sobre un modelo más efectivo de tratamiento resocializador- la justicia restaurativa- construyendo con ello un discurso de "cultura de paz", que desprenden cada una de sus páginas.

Es cierto que en los últimos años han sido abundantísimas las obras sobre justicia restaurativa y mediación penal que han visto la luz, todas con un abordaje científico merecedor de los más altos elogios. El acercamiento desde múltiples perspectivas científicas nos ha nutrido de conocimientos y nos ha hecho reflexionar acerca de la necesidad de realizar un cambio en nuestra manera de enfocar el sistema penal.

Revista Española de Investigación Criminológica

Recensión 1, Número 17 (2019)

https://doi.org/10.46381/reic.v17i0.231

www.criminologia.net

ISSN: 1696-9219 
Sin embargo, somos conscientes de que ningún cambio en este sentido va a ser efectivo sin una modificación radical de nuestro propio conocimiento y nuestra cultura. Un cambio de enfoque requiere no solamente una transformación del propio sistema penal, sino de la propia sociedad que lo integra.

$\mathrm{Y}$ en este sentido, sin duda, esta obra logra romper dichos anclajes y poner al lector en el portal de entrada por el que debe pasar todo operador de conflictos.

En obras anteriores, Calvo Soler se había adentrado con éxito en estas materias. Sus obras "Mapeo de conflictos" (2014) o "Donde la justicia no llega: cuando el proceso judicial no acompaña" (2018) son claros ejemplos de una serena y seria reflexión acerca de los métodos adecuados de resolución de conflictos en la actualidad.

En este caso, aunque aborda concretamente la justicia restaurativa en su dimensión de plasmación en prácticas restaurativas en el ámbito de la justicia de menores, creemos firmemente que la influencia de las reflexiones vertidas en esta obra no se va a ver limitada únicamente a este campo, la justicia de menores, sino que logra servir de referente a cualquier tipo de práctica restaurativa, ya sea esta desarrollada en un contexto judicial como extrajudicial. Es más, va a servir para lograr un enfoque positivo en el análisis de cualquier tipo de conflicto, si efectivamente el operador quiere conseguir la finalidad de pacificar, que debe ser inherente al tratamiento de los mismos.

El autor desgrana sus reflexiones en lo que él denomina "trazos", distribuyendo sus reflexiones en cuatro, para enumerar en el quinto "trazo" un catálogo de retos, centrados en destruir los falsos paradigmas sobre la filosofía restaurativa.

El primero de ellos aborda los conceptos básicos de los que debe partirse, sin duda, a la hora de analizar un sistema restaurativo. La claridad de las ideas y el esfuerzo reflexivo con el que son tratados, establecen un punto clave para el posterior desarrollo de los restantes "trazos". En este primer trazo la comparativa entre los elementos del sistema retributivo y el restaurativo conforman una visión analítica que favorece la profunda reflexión acerca del tema que aborda, incidiendo muy críticamente en los errores que la inclusión rápida y poco reflexiva de prácticas restaurativas en sistemas tradicionalmente retributivos está 
suponiendo, lo que sin duda está poniendo en peligro la eficiencia de aquellas y, sobre todo, su proyección futura.

La inclusión de prácticas restaurativas en contextos retributivos corre el riesgo, como señala el autor, de convertirse en un complejo de mecanismos de derivación, que en la mayoría de las ocasiones simplemente sustituyen al catálogo de sanciones legales.

Lo que el autor defiende es la construcción de un sistema restaurativo a modo de justicia terapéutica, de manera que, aunque la inclusión de dichas prácticas se engarce en un sistema clásico, contribuya a su propia contextualización, ayudando al sistema receptor a acoger principios acordes con aquella. De otra manera, la inclusión sólo actuará de parche sin dotar de un nuevo sentido a sus respuestas.

En definitiva, de lo que se trata es de traspasar la idea de resolución para acometer de una vez por todas la esencia de la gestión del conflicto. Para ello, nos coloca en un escenario donde dicha gestión pueda ser realizada de manera adecuada, trabajando con cada uno de los elementos del conflicto penal: la comunidad, la víctima, el victimario, la idea de reconocimiento, daño...

Para él, un modelo basado en la gestión aborda, analiza y trabaja sobre todos los elementos del conflicto sin dar por válida la visión formalista de los mismos: actor, parte pasiva, objeto de conflicto. Sin duda este paso es el fundamental para afrontar de una manera eficiente los conflictos.

El autor marca, además, una diferenciación que va a ser el hilo conductor de toda la obra, por un lado, las llamadas "estrategias de gestión" y por otro las "estrategias restaurativas". Las primeras entran a operar sólo y cuando en el conflicto concreto no se den las condiciones adecuadas para poder trabajar desde un enfoque restaurativo, mientras que las segundas hacen referencia a los pasos y condiciones del propio trabajo restaurativo. A partir de ahí el autor desarrolla los siguientes trazos.

La razón por la que el autor ciñe su discurso al campo de la justicia juvenil es, en sus propias palabras, que el sesgo pedagógico, siendo un rasgo común a lo restaurativo, es más evidente y eficiente en el caso de los jóvenes. Con los adultos, además del aprendizaje hay que afrontar un proceso de desestructuración, cosa que en el caso de los menores no es

Revista Española de Investigación Criminológica

Recensión 1, Número 17 (2019)

https://doi.org/10.46381/reic.v17i0.231

www.criminologia.net

ISSN: 1696-9219 
necesario, al menos en la mayoría de las situaciones. Además, la comunidad tiene una mayor disposición a participar con los jóvenes que con los adultos. Por ello, y en la actualidad, el contexto en que se desenvuelve el trabajo restaurativo con jóvenes se muestra más amable a este enfoque, facilitando sin duda las labores tanto de gestión como de estrategias restaurativas.

El análisis que realiza de cada uno de los elementos subjetivos del conflicto penal, en el trazo segundo, es verdaderamente atrayente, más cuando los sistemas clásicos de justicia penal no se detienen en estos aspectos tan importantes de tener en cuenta. Y es que dichos aspectos son sin duda los elementos básicos de los que va a depender el éxito o fracaso de un sistema que quiera verdaderamente resolver de una manera completa el conflicto. Defiende la exploración profunda de los mismos, para, trascendiendo de lo puramente normativo, encontrar la pacificación no sólo de los sujetos directamente afectados, sino que también contando con el trabajo conjunto de la comunidad se llegue a la satisfacción de esta última.

Es por tanto a partir de esta exploración del conflicto (concepto que encontramos en el novedoso anteproyecto de Ley para el fomento de la mediación) que el autor justifica la misma para encontrar el nivel de madurez de las condiciones que deben darse en los sujetos, y así poder trabajar con ellos en prácticas restaurativas.

En el caso de la víctima se requiere que esté en una situación de legitimación interna, a la par de que cumpla con unos mínimos de inteligencia emocional, y obviamente con su voluntad de participación.

Desde el victimario son imprescindibles que se observen tanto el reconocimiento de los hechos como un sentimiento de responsabilización, lo que nos llevaría al compromiso de reparación.

Y en cuanto a las condiciones de la comunidad, erigida tanto como víctima refleja o directa, como a un recurso indispensable en la estrategia restaurativa, destaca dos especialmente significativas: que la comunidad realice una valoración positiva de las condiciones de los restantes sujetos y la llamada monoliticidad (búsqueda de objetivos comunes). 
Si en este trazo Calvo Soler desgrana los resultados del trabajo exploratorio, en el siguiente, el tercero, se centra en determinar cuáles deben ser las gestiones a realizar para el caso en que alguna de las condiciones no se cumpla. En definitiva, estudia cuales deben ser las estrategias de gestión.

El proceso exploratorio se torna así en el elemento previo y fundamental para lograr un análisis que sirva a la gestión completa de las condiciones. En este punto y sobre todo para lograr un análisis completo, subraya la importancia de encontrar en las narrativas elementos de contextualización. Con ello se consigue indagar en conflictos previos subyacentes, ya que los intereses ocultos o simbólicos pueden ser también graves escollos a la hora de realizar la gestión de las condiciones.

Este tercer trazo incluye una serie de epígrafes dedicados a la noción de conflicto y sus elementos, para dotar a las exploraciones de una sistemática óptima.

Trazo cuarto: Estrategias restaurativas.

El objeto de este cuarto trazo son los presupuestos del sistema de prácticas restaurativas comenzando con el análisis de la estructura de aquella. Tradicionalmente aunamos la existencia de dichas prácticas con el propio sistema penal. Sin embargo, el autor destaca que la necesidad de dicho maridaje no tiene un fundamento sólido, es más, muestra y demuestra como dicha dependencia puede llegar a ser incluso contraproducente.

Prueba de ello es la reflexión constante acerca de la necesidad ineludible de que las prácticas restaurativas eficientes deben conectarse con una red comunitaria de recursos disponibles, llevando la filosofía restaurativa a cada uno de ellos, a la vez que se utilizan como herramienta del sistema.

Por último, realiza un análisis de los factores que deben darse en los operadores del sistema, enunciando: la creatividad, el pensamiento crítico, la empatía, la capacidad para diversificar la comunicación y construir procesos, como también el manejo de la incertidumbre.

Entrando en el análisis de la dinámica, analiza los primeros encuentros y sus finalidades: análisis del contexto, reunión informativa y reuniones exploratorias.

Revista Española de Investigación Criminológica

Recensión 1, Número 17 (2019)

https://doi.org/10.46381/reic.v17i0.231

www.criminologia.net

ISSN: 1696-9219 
Como señala el autor, el operador restaurativo debe "ser consciente en todo momento de lo que está buscando y de aquello que está sucediendo antes o durante el espacio restaurativo". En este sentido debe perseguirse un equilibrio entre "prever lo previsible y estar preparado para lo imprevisible".

Así, planificación, visión, aprendizaje y proceso colectivo se convierten en las máximas de las estrategias del operador restaurativo.

La gran importancia de la comunidad como estrategia, sin duda, uno de los factores que culturalmente más pueden impedir un final eficiente en estas prácticas restaurativas, se torna en el Talón de Aquiles y en el centro de atención de este cuarto trazo. Lo que él viene en llamar la comunidad de aprendizaje es el foco de la última parte de este trazo. La comunidad como sujeto implicado en el conflicto es el recurso o instrumento más importante para la consecución de la pacificación y su estabilidad. Sin una comunidad que interactúe en las prácticas restaurativas y sin la influencia recíproca de ambas cualquier intento de potenciar lo restaurativo será una pura entelequia.

La importancia que los elementos sociales, psicológicos y comunitarios tienen para alcanzar la paz social no puede quedar sólo en manos de la norma y el proceso. La comunidad que quiere alcanzarla ha de implicarse activamente.

Como ya hemos señalado, la obra culmina poniendo de manifiesto los riesgos que suponen para la implantación de estos sistemas los graves errores del imaginario colectivo acerca del significado, contenido y alcance de la filosofía restaurativa. Así, a modo de mantra, desgrana el autor lo que no debe ser considerado como tal, con una finalidad tanto clarificadora como de restar fuerza a los mismos. 